\title{
Melting above the anhydrous solidus controls the location of volcanic arcs
}

Philip C. England ${ }^{1}$ \& Richard F. Katz ${ }^{1}$

${ }^{1}$ Department of Earth Sciences, Parks Road, Oxford, OX1 3PR

This is an author-prepared copy of the final version of this paper. The published version is in Nature, v467, 700-704, doi:10.1038/nature09417

http://www.nature.com/nature/journal/v467/n7316/full/nature09417.html

Segregation of magma from the mantle in subduction zones is a primary mechanism for chemical differentiation of the planet. Fundamental aspects of subduction zones, in particular the processes by which melt forms and travels to the Earth's surface, remain obscure. Systematics in the location of volcanic arcs, the surface expression of this melting, are widely considered to present a clue to processes taking place at depth, but many mutually incompatible interpretations can be found in the current literature (e.g. refs. ${ }^{1-6}$ ). We discriminate rigorously between those interpretations by the use of a simple scaling argument derived from a realistic mathematical model of heat transfer in subduction zones. The locations of the arcs cannot be explained by the release of fluids in reactions taking place near the top of the slab. Instead, the sharpness of the volcanic fronts, together with the systematics of their locations, require that arcs must be located above the place where the boundary defined by the anhydrous solidus makes its closest approach to the trench. We show that heat carried by magma rising from this region is sufficient to modify the thermal structure of the wedge and determine the pathway through which both wet and dry melts reach the surface.

Volcanic arcs are characterized by sharp fronts whose locations may be described, with misfits of no more than a few kilometres, by small circles on the Earth's surface (Figure 1 and refs. ${ }^{7,8}$ ); furthermore, the depth of the top of the slab beneath these fronts falls in a narrow range $\left(\sim 120 \pm 40 \mathrm{~km}^{1,3,5}\right)$. The sharpness of the volcanic fronts implies that a key process in the generation or transport of magma is similarly focused beneath the arcs, but there is no consensus as to what that process may be. A wide range of metamorphic and melting reactions, either in the slab or in the mantle wedge, have been proposed as candidates for that process. Some authors suggest that the arcs lie above places where the degree of melting in the mantle wedge becomes high enough for the melt to segregate from the solid ${ }^{2,4}$. Others suggest that the locations of arcs are determined by the release of fluid near the top of the slab in reactions that are either strongly pressure-dependent ${ }^{1,3,5}$, or strongly temperature-dependent ${ }^{6,9}$. None of these suggestions has, however, produced a successful quantitative prediction of the location of volcanic arcs. Here we take a different approach; starting with the observed correlation between the descent speed of the slab and its depth beneath the volcanic $\operatorname{arcs}^{8}$, we use a simple mathematical model to fit the data and reveal the petrological processes responsible for the locations of the arcs. 


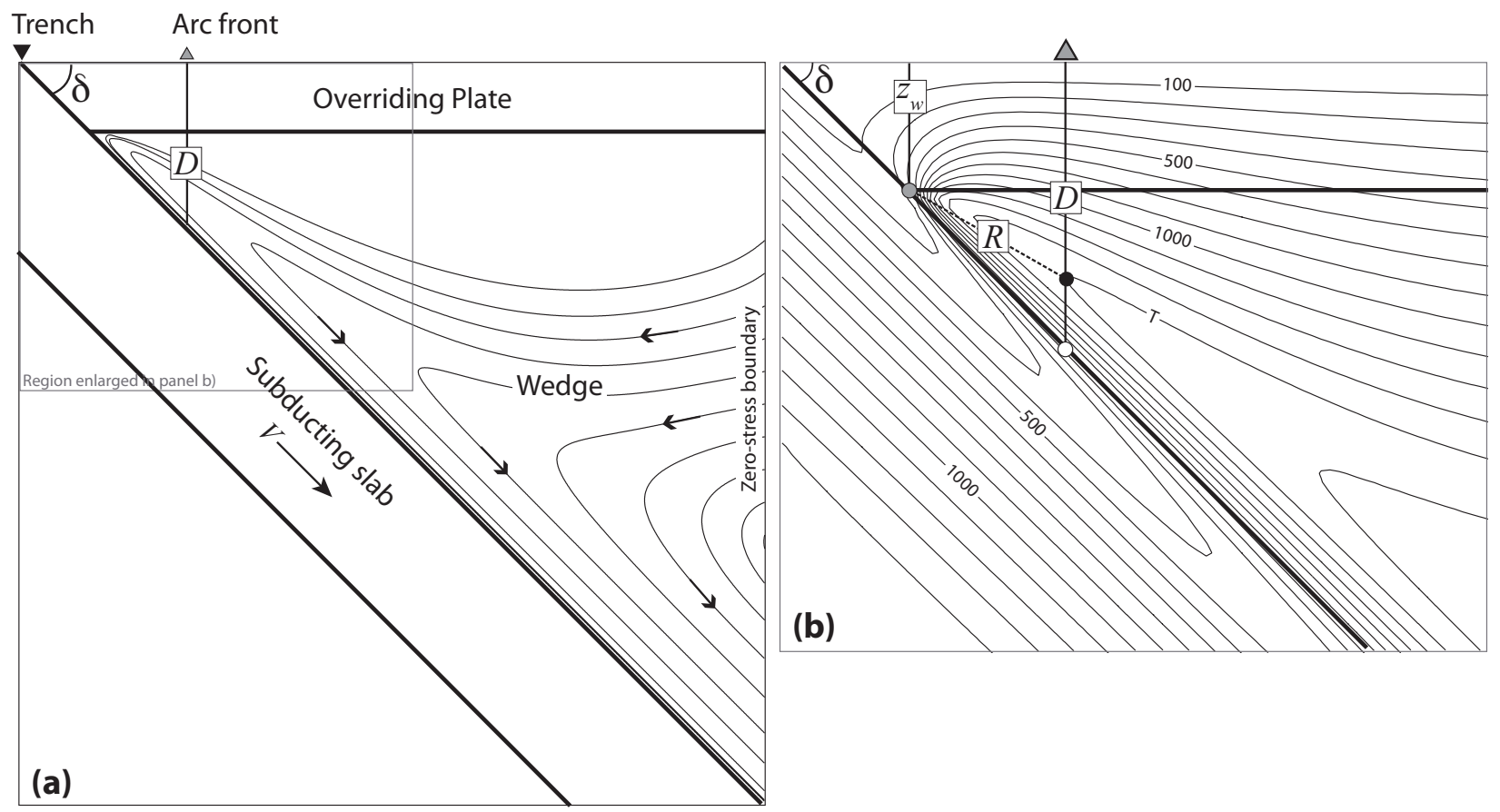

Figure 1: Idealized cross-sections of a subduction zone, drawn perpendicular to the trench and the island arc. Panel (a) Two plates converge at a speed $V$, with the slab of oceanic lithosphere being subducted at an angle $\delta$ beneath the overriding plate. The arc front is a zone a few kilometres wide, across which volcanic activity begins as one moves away from the trench; it lies at a distance $D$ above the top of the slab. The relative motion between slab and overriding plate generates a creeping flow in the wedge of mantle between them, which follows stream lines, shown as curved lines. The corner of the wedge is at a depth is $z_{w}$. Panel (b) Temperature structure; isotherms are shown at intervals of $100^{\circ} \mathrm{C}$. A schematic isotherm, labelled $T$, has its closest approach to the wedge corner (its "nose") immediately beneath the volcanic front, at a distance $R$ from the corner (black circle). An open circle marks the top of the slab directly below the corner of this isotherm, at a depth $D$ below the surface. The distance $R$ cannot be determined by observation, but is similar to $R_{D}=\left(D-z_{w}\right) / \sin (\delta)$ the radial distance of the top of the slab (open circle) from the wedge corner. 

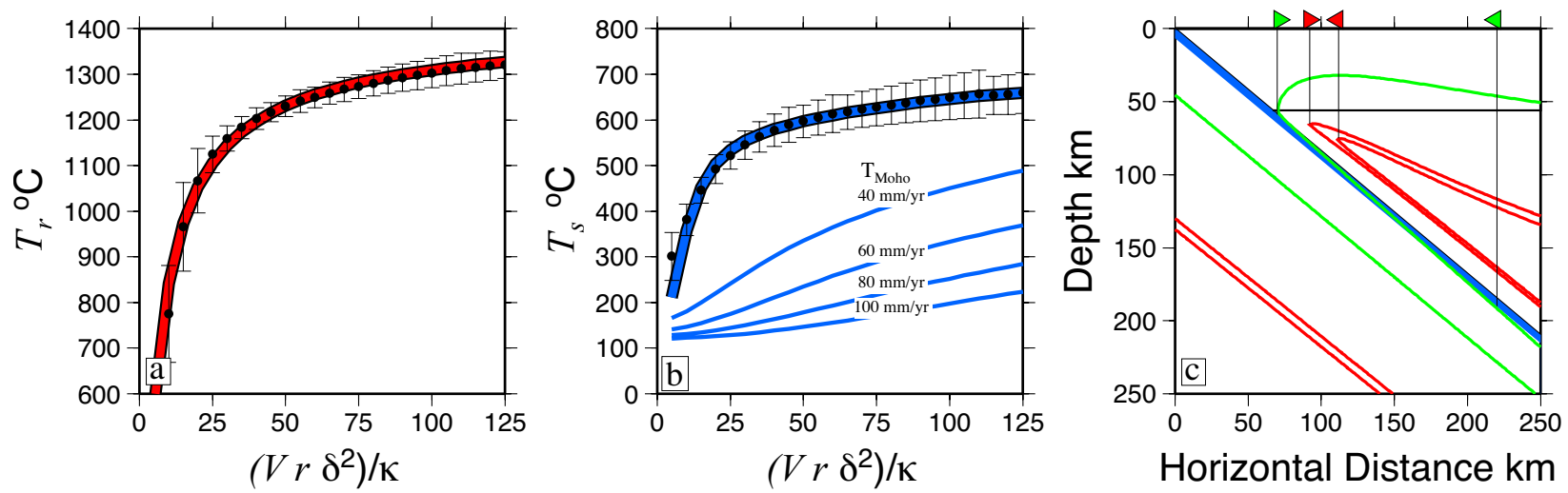

Figure 2: Scaling relations for temperatures in the core of the mantle wedge, and at the top of the slab. Panel (a) Maximum temperature in the wedge, $T_{r}$, as a function of dimensionless distance from the wedge corner, $\operatorname{Vr} \delta^{2} / \kappa$, where $V$ is convergence speed, $\delta$ is dip of the slab, and $\kappa$ is thermal diffusivity. Dots with error bars indicate the averages and standard deviations of $T_{r}$, from calculations in which $V$ varies from $10 \mathrm{~mm} / \mathrm{yr}$ to $100 \mathrm{~mm} / \mathrm{yr}$, in steps of $10 \mathrm{~mm} / \mathrm{yr}$, while $\delta$ varies from $20^{\circ}$ to $70^{\circ}$ in steps of $10^{\circ}$. The red line corresponds to the theoretical expression for $T_{r}$ (equation 1), with $T_{0}=1420^{\circ} \mathrm{C}, B=3.3$, and $\beta=-0.8$. b) Panel (b) as a), but for temperatures within the slab. Thick blue line corresponds to the theoretical expression for $T_{s}$, the temperature on the top of the slab (equation 2), with $C=1.4$, and $\gamma=-0.06$. Thin blue lines indicate the temperatures at the base of the crust $(7 \mathrm{~km}$ below the top of the slab) for convergence rates $V$ of 40-100 mm/yr. Panel (c) The temperature structure near the wedge corner for a calculation with a convergence speed, $V$, of $80 \mathrm{~mm} / \mathrm{yr}$ and a slab dip of $40^{\circ}$. The location of the $500^{\circ} \mathrm{C}$ isotherm is shown by green lines and the $1225^{\circ} \mathrm{C}$, and $1275^{\circ} \mathrm{C}$ isotherms are shown by red lines. Green arrowheads show the horizontal extent over which some part of the oceanic crust is at a temperature of $500^{\circ} \mathrm{C}$. Red arrowheads show the range over which the maximum temperature in the mantle wedge lies between $1225^{\circ} \mathrm{C}$ and $1275^{\circ} \mathrm{C}$ (a typical range of temperature represented by the error bars in Figure $3 b$ ). Uncertainties in the temperatures arising from idealizations in the model are discussed in the Supplementary Material, Section B2.

Although calculations of the full temperature field in subduction zones require numerical models ${ }^{10}$, their results can be encapsulated in simple scaling relations which show ${ }^{11}$ that temperatures within the mantle wedge and at the top of the slab depend upon a single parameter, $\operatorname{Vr} \delta^{2} / \kappa$. Here $V$ is the convergence rate across the plate boundary, $\delta$ is the dip of the slab, $r$ is the radial distance from the wedge corner (Figure 1), and $\kappa$ is the thermal diffusivity of the mantle. In this scaling, the maximum temperature in the mantle wedge $T_{r}$ is given by

$$
T_{r} \sim T_{0} \exp \left[-B\left(\frac{V r \delta^{2}}{\kappa}\right)^{\beta}\right],
$$

while the temperature $T_{s}$ at the top of the slab is

$$
T_{s} \sim \frac{T_{r}}{1+C\left(V r \delta^{2} / \kappa\right)^{\gamma}},
$$

where $T_{0}$ is a scale temperature, and $B, C, \beta$ and $\gamma$ are constants whose values depend on the details of the flow near the top of the slab. This scaling was initially derived for a model of subduction zones that treated the mantle as a constant-viscosity fluid ${ }^{11}$; we show here that these relations also hold for the case in which the viscosity has a dependence on temperature that is appropriate for the upper mantle (Figure 2 and Supplementary Material).

Precise earthquake hypocentral locations ${ }^{12}$ show that the depth $D$ to the top of the slab beneath the 

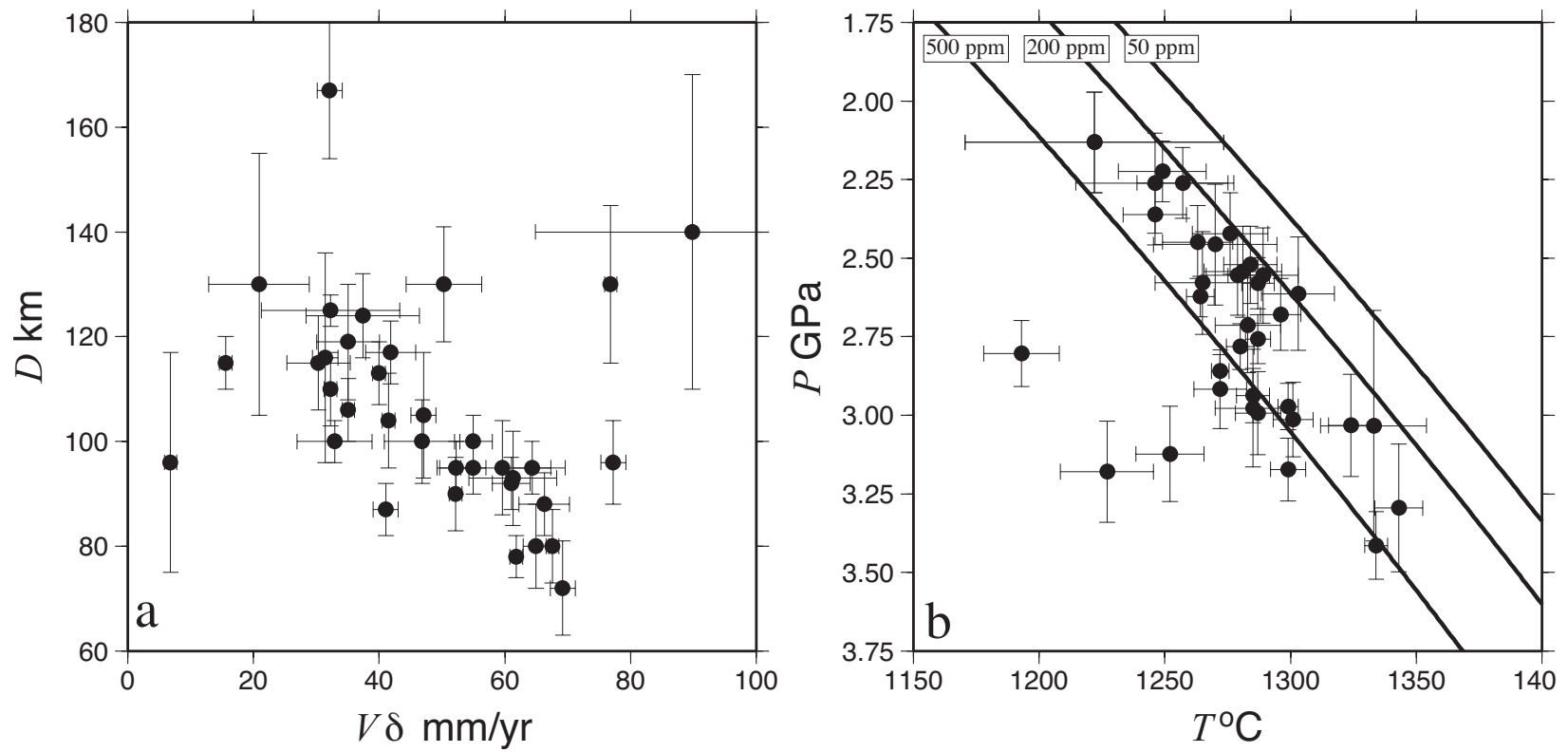

Figure 3: Systematic variation in depth to the slab beneath volcanic arcs, and its relation to pressure-temperature conditions beneath the arcs. Panel (a) Depth to the top of the slab beneath volcanic arcs (see Supplementary Material), plotted against $V \delta$ (equation 3). Panel (b) Conditions beneath the volcanic fronts estimated from calculations with descent speed, $V$, and dip, $\delta$, corresponding to the arcs investigated in this paper. Dots show the maximum temperature in the mantle wedge beneath the front, and the pressure at which that temperature is reached. For each calculation, the arc front is taken to lie immediately above the place where the top of the slab reaches the depth $D$; error bars represent the range in maximum temperature (and the pressure at which it is reached) associated with a $\pm 5 \mathrm{~km}$ uncertainty in the horizontal location of the arc front. Lines labelled 50, 200, and $500 \mathrm{ppm}$ correspond to the solidi for peridotite containing these fractions of water ${ }^{15}$.

fronts of volcanic arcs is constant, to within a few kilometres, along individual segments of arc but varies from 80 to $160 \mathrm{~km}$ between different segments ${ }^{8,13}$ (Figure 3). This variation rules out the hypothesis that the arcs are located above the place where the top of the slab reaches a critical pressure corresponding to a single dehydration reaction ${ }^{1,3,5}$. We may also rule out the hypothesis that the release of fluids by temperature-dependent reactions near the top of the slab determines the location of arcs (e.g. ref. ${ }^{6}$ ). The top of the slab lies within a thermal boundary layer a few tens of kilometres thick, across which there is a temperature difference of $\sim 1000^{\circ} \mathrm{C}$. Because isotherms within this boundary layer are almost parallel to the slab, any given temperature will be found over a very large range of pressure (Figure $2 b, c)$. Therefore, temperature-dependent processes taking place near the top of the slab cannot be sharply localized, but must occur over a broad range of down-dip distances ${ }^{14}$.

In contrast, the steep lateral thermal gradients in the core of the mantle wedge provide a setting in which localization of temperature-dependent processes is likely ${ }^{2,4}$. The maximum temperature in the mantle wedge depends on the dimensionless distance from the wedge corner $V r \delta^{2} / \kappa$ (equation 1, Figure 2a). Accordingly, we should expect that if a temperature-dependent process is localized beneath the arc, the relevant isotherm will reach its closest approach to the wedge corner (which we refer to below as its "nose") at a distance $R$ that is inversely proportional to $V \delta^{2}$. Although $R$ cannot be measured directly, it is very similar to the radial distance $R_{D}=\left(D-z_{w}\right) / \sin (\delta)$ of the top of the slab from the wedge corner at that 
location (Figure 1), thus

$$
\frac{V R_{D} \delta^{2}}{\kappa} \sim \frac{V \delta^{2}\left(D-z_{w}\right)}{\kappa \sin (\delta)} \sim \frac{V \delta\left(D-z_{w}\right)}{\kappa}
$$

Here, $z_{w}$ is depth to the wedge corner, and we have made the small-angle approximation $\sin (\delta) \sim \delta$. Hence, for $z_{w}$ constant or varying little in comparison with $D$, we should expect $D$ to vary inversely with $V \delta$.

We can make a reliable determination of $D$ for 35 arcs (Supplementary Material); the Spearman rankorder correlation coefficient between $D$ and $V \delta$ for these arcs (Figure 3b) is -0.33 , which is significant at the $95 \%$ level of confidence. The significance of the correlation is sensitive to the presence of five arcs with large uncertainties in $D$ (identified in Figure S1); the confidence level for the correlation exhibited when these five arcs are excluded is above $99.9 \%$. Thirty arc segments, with a total length of $22,000 \mathrm{~km}$, exhibit the relationship between $D$ and $V \delta$ that is predicted by equation 3, whereas five arc segments with a total length of $\sim 4,000 \mathrm{~km}$, do not lie on the trend. (See Supplementary Material for further discussion.) We therefore conclude that the global systematics ${ }^{8,13}$ strongly support the hypothesis that the locations of volcanic arcs are determined by a temperature-dependent process taking place in the wedge ${ }^{2,4}$.

To estimate the conditions at which this process takes place, we carried out calculations of steadystate wedge thermal structure for combinations of slab dip and convergence rate corresponding to the 35 individual arcs in Figure 3a. The maximum temperature in the column of mantle beneath the location of the arc, and the pressure at which that temperature is reached, form an array between about $1250^{\circ} \mathrm{C}$ and $1325^{\circ} \mathrm{C}$, and 2-3.5 GPa (Figure $3 \mathrm{~b}$ ) that corresponds closely to the range of P-T conditions for the melting of peridotite in the presence of between 200 and $500 \mathrm{ppm} \mathrm{H}_{2} \mathrm{O}^{15}$. These water contents are about ten times lower than the concentrations estimated for wet melting beneath arcs, but are representative of the water contents of the mantle beneath back-arc basins ${ }^{16}$. In what follows, we refer to such $\mathrm{H}_{2} \mathrm{O}$ concentrations as "anhydrous" to distinguish them from the hydrous melts that are volumetrically dominant in the wedge.

It is generally accepted that hydrous melting pervades the mantle wedge, but it has been suggested that the arc front is located somewhere above the region in which the temperature in the wedge exceeds the anhydrous solidus, because the degree of hydrous melting increases rapidly there ${ }^{2,4}$. Melt may also be produced in this temperature range as a result of anhydrous decompression melting of upwelling mantle; indeed, the existence of distinct regimes of melting beneath the arcs has been inferred from the eruption of low-water-content, tholeiitic melt from arc volcanoes that also erupt typical hydrous melts ${ }^{17-21}$. Geodynamic models show, however, that either type of melting occupies a broad region of the wedge core, extending from beneath the arc front toward the back-arc ${ }^{22,23}$. Any explanation for the localisation of the arc fronts that invokes melts produced over this broad volume must therefore include a mechanism for focusing the melts to the line beneath the arcs.

Interaction of rising magma with the thermal boundary layer at the top of the wedge provides this mechanism. As the rising magma hits this boundary, it begins to crystalise, forming an impermeable barrier above a sloping, high-porosity channel ${ }^{23,24}$. Such interaction requires sufficient crystallization to seal the pore space against vertical magmatic flow ${ }^{25}$; this condition is met at temperatures above the anhydrous solidus, where isobaric productivity is high and small decreases in temperature result in significant crystallization, but not below it, where isobaric productivity is low ${ }^{15,26}$. We therefore propose, as sketched in Figure $4 \mathrm{a}$, that the high-porosity channel terminates at the nose of the anhydrous solidus. This nose is 

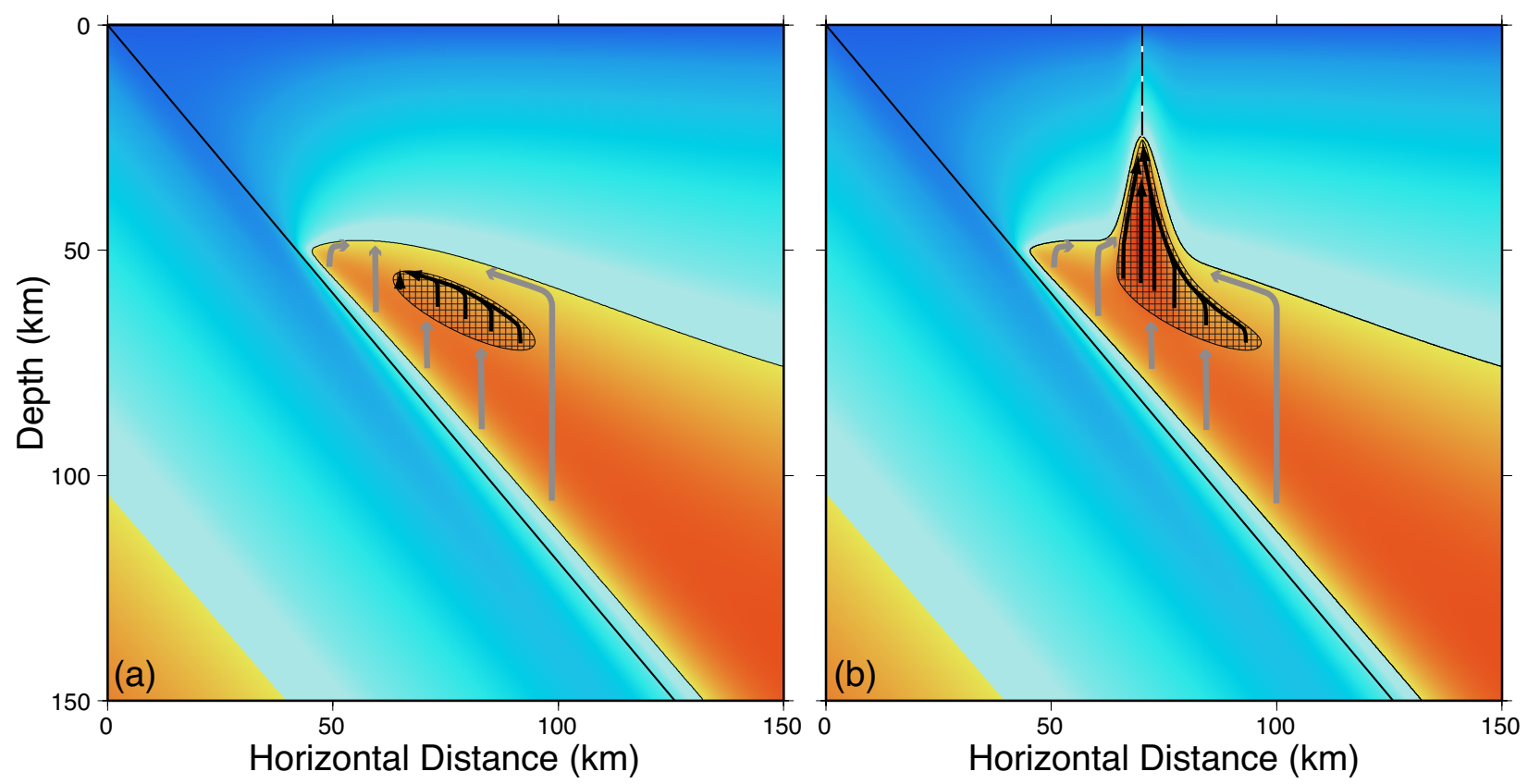

Figure 4: A sketch of the process that determines the position of volcanoes. The top of the slab is indicated by the straight black line. The cross-hatched region is above the nominally anhydrous solidus of ambient mantle; the black line separating the blue and yellow-to-red colours represents the water-saturated solidus of the mantle. Panel (a) shows the distribution of temperature and melting without heat transport by migrating melt; arrows show melt formed above the nearly-dry solidus rising, then travelling through a high-porosity channel to the nose of the solidus. Panel (b) is a schematic depiction of how melt transport, indicated by arrows, would modify that distribution (see Supplementary Material). Magma rising from the nose of the dry solidus heats the region immediately above, deflecting upwards the dry and wet solidi so that they both reach their shallowest depth in the same horizontal location. Each type of melt travels laterally and upward along its respective solidus toward this location. Melts eventually penetrate the lithosphere by hydrofracture and dyking. In the case of low permeability in the wedge, advection of melt by the moving mantle can cause the trajectories to deviate horizontally ${ }^{23}$; that process could affect the details of this sketch.

controlled by temperature, so its location will depend upon $V \delta$, consistent with the observations (Figure 3).

If the advective flux of heat carried by the magma is of the same order as the vertical conductive heat flux, the melt arriving at the nose of the solidus will erode the cold boundary layer at the top of the wedge and bow upward the solidi for both wet and dry melting. The rate of heat transfer by the melt is $\sim M L$, where $M$ is the mass flow of magma and $L$ is its latent heat per unit mass. The conductive heat flux is $\sim k \Delta T / h$, where $k$ is thermal conductivity, $\Delta T$ is the temperature difference between the solidus and the surface temperature, and $h$ is the depth to the nose of the solidus beneath the arc. This argument, expanded in the Supplementary Material, shows that the ratio of these two quantities

$$
\mathcal{M}=\frac{M L h}{k \Delta T}
$$

controls the efficiency of thermal erosion. For reasonable estimates of the rate of mass flux into arc volcanoes ${ }^{22,27-30} \mathcal{M} \sim 0.8$, which is sufficient to perturb upward the location of the anhydrous solidus by $>40 \%$ of its 
depth (Figure S4). In consequence, all melt migrates towards the place where the solidus is bowed upward - including melt generated closer to the trench (Figure 4b).

In summary, the observed systematics in the location of the volcanic arcs shows that the mechanism whereby the melt reaches the Earth's surface are controlled by the dynamics of the wedge, not by any locally concentrated release of fluid in reactions taking place near the top of the slab. In our model, magma formed at temperatures above the anhydrous solidus in the wedge is focused trench-ward, to the nose of the region bounded by that solidus. Above the nose, thermal erosion by rising magma establishes the pathway that all melts, hydrous or anhydrous, take to reach the arc volcanoes. Future analysis, including calculations that incorporate the physics of melt migration ${ }^{31}$, will help to clarify this hypothesis.

\section{Summary of Methods}

\section{Calculations of Thermal Structure of Subduction Zones}

Our calculation of the thermal structure of subduction zones employs a finite-volume discretization of the incompressible, variable-viscosity Stokes equation and steady-state, advection-diffusion energy equation on a uniformly spaced, staggered cartesian mesh $^{32}$. It uses a Newton-Krylov solver provided by the Portable, Extensible Toolkit for Scientific Computation ${ }^{33,34}$. The code has been benchmarked against other numerical solutions for the this type of problem ${ }^{10}$. The viscosity $\eta$ is given by an Arrhenius law for diffusion creep of olivine

$$
\eta=A \exp \left(\frac{E+P V^{*}}{R T}\right)
$$

with activation energy $E$ and activation volume $V^{*}$ of $375 \mathrm{~kJ} / \mathrm{mol}$ and $5 \times 10^{-6} \mathrm{~m}^{3} / \mathrm{mol}$, respectively, and pre-exponential $A=1.8 \times 10^{7} \mathrm{~Pa}^{35,36}$.

The domain is 600 by $600 \mathrm{~km}$, oriented as shown in Figure 1, with a mesh spacing of $1 \mathrm{~km}$. We have checked convergence of our solutions by comparing them, for combinations of parameters that span the range of interest, against solutions with mesh spacing of $0.5 \mathrm{~km}$. We find differences between the two meshes at the level of less than $10^{\circ} \mathrm{C}$ between temperatures calculated on the top of the slab or near the wedge corner.

\section{Measurement of Depth to Top of Slab Beneath Arcs}

We apply the methods of ref. ${ }^{8}$ to the 45 arc segments studied by ref. ${ }^{13}$. For each arc segment we formed cross-sections of the seismicity and estimated $D$ as described by ref. ${ }^{8}$. We used the tables given in the supplementary information of ref. ${ }^{13}$ to check whether the segment boundaries of the two studies agreed; except where noted in the table in the Supplementary Material, the disagreements were minor and we used the segment boundaries of ref. ${ }^{8}$.

1. Gill, J. Orogenic Andesites and Plate Tectonics (Springer-Verlag, New York, 1981). 
2. Kushiro, I. A petrological model of the mantle wedge and lower crust in the Japanese island arcs. In Mysen, B. (ed.) Magmatic Processes: Physicochemical Principles, vol. 1, 165-181 (Geochem. Soc. Spec. Pub;, 1987).

3. Tatsumi, Y. \& Eggins, S. Subduction Zone Magmatism (Blackwell Science, Cambridge, MA, 1995).

4. Schmidt, M. \& Poli, S. Experimentally based water budgets for dehydrating slabs and consequences for arc magma generation. Earth Planet. Sci. Lett. 163, 361-379 (1998).

5. Tatsumi, Y. The subduction factory: How it operates in the evolving Earth. GSA Today 15, 4-10 (2005).

6. Grove, T. L., Till, C. B., Lev, E., Chatterjee, N. \& Médard, E. Kinematic variables and water transport control the formation and location of arc volcanoes. Nature 459, 694-697 (2009).

7. Tovish, A. \& Schubert, G. Island arc curvature, velocity of convergence and angle of subduction. Geophys. Res. Letts. 5, 329-332 (1978).

8. England, P. C., Engdahl, E. R. \& Thatcher, W. Systematic variation in the depths of slabs beneath arc volcanoes. Geophys. J. Int. 156, 377-408 (2004).

9. Ulmer, P. \& Trommsdorff, V. Serpentine stability to mantle depths and subduction-related magmatism. Science 268, 858-861 (1995).

10. van Keken, P. et al. A community benchmark for subduction zone modeling. Phys. Earth Planet. In. 171, 187-197 (2008).

11. England, P. \& Wilkins, C. A simple analytical approximation to the temperature structure in subduction zones. Geophys. J. Int. 159, 1138-1154 (2004).

12. Engdahl, E., van der Hilst, R. \& Buland, R. Global teleseismic earthquake relocation with improved travel times and procedures for depth determination. Bull. Seismol. Soc. Am. 88, 722-743 (1998).

13. Syracuse, E. M. \& Abers, G. A. Global compilation of variations in slab depth beneath arc volcanoes and implications. Geochem. Geophys. Geosys. 7, 18 (2006).

14. England, P. C. \& Katz, R. F. Communication arising. Nature (2010).

15. Katz, R., Spiegelman, M. \& Langmuir, C. A new parameterization of hydrous mantle melting. Geochem. Geophys. Geosys. 4 (2003).

16. Kelley, K. A. et al. Mantle melting as a function of water content beneath back-arc basins. J. Geophys. Res. 111, 27 (2006).

17. Baker, M., Grove, T. \& Price, R. Primitive basalts and andesites from the Mt. Shasta region, N. California - products of varying melt fraction and water content. Contrib. Mineral. Petrol. 118, 111-129 (1994).

18. Sisson, T. \& Bronto, S. Evidence for pressure-release melting beneath magmatic arcs from basalt at Galunggung, Indonesia. Nature 391, 883 (1998).

19. Elkins-Tanton, L., Grove, T. \& Donnelly-Nolan, J. Hot, shallow mantle melting under the Cascades volcanic arc. Geology 29, 631-634 (2001). 
20. Cameron, B. et al. Flux versus decompression melting at stratovolcanoes in southeastern Guatemala. $J$. Volcanology and Geothermal Research 21-50 (2003).

21. Tatsumi, Y. \& Suzuki, T. Tholeiitic vs calc-alkalic differentiation and evolution of arc crust: Constraints from melting experiments on a basalt from the Izu-Bonin-Mariana arc. J. Petrology 50, 1575-1603 (2009).

22. Conder, J., Wiens, D. \& Morris, J. On the decompression melting structure at volcanic arcs and back-arc spreading centers. Geophys. Res. Letts. 29, 1727 (2002).

23. Cagnioncle, A.-M., Parmentier, E. M. \& Elkins-Tanton, L. T. Effect of solid flow above a subducting slab on water distribution and melting at convergent plate boundaries. J. Geophys. Res. 112, 19 (2007).

24. Sparks, D. \& Parmentier, E. Melt extraction from the mantle beneath spreading centers. Earth Plan. Sci. Lett. 105, 368-377 (1991).

25. Spiegelman, M. Physics of melt extraction: theory, implications, and applications. Phil. Trans. R. Soc. London A 342, 23-41 (1993).

26. Hirschmann, M. M., Asimow, P. D., Ghiorso, M. S. \& Stolper, E. M. Calculation of peridotite partial melting from thermodynamic models of minerals and melts. III. Controls on isobaric melt production and the effect of water on melt production. J. Petrol. 40, 831-851 (1999).

27. Crisp, J. Rates of magma emplacement and volcanic output. J. Volcanology and Geothermal Research 20, 177-211 (1984).

28. Reymer, A. \& Schubert, G. Phanerozoic addition rates to the continental crust and crustal growth. Tectonics 3, 63-77 (1984).

29. Dimalanta, C., Taira, A., Yumul, G., Tokuyama, H. \& Mochizuki, K. New rates of western Pacific island arc magmatism from seismic and gravity data. Earth Planet. Sci. Lett. 202, 105-115 (2002).

30. White, S., Crisp, J. \& Spera, F. Long-term volumetric eruption rates and magma budgets. Geochem. Geophys. Geosys. 7, Q03010 (2006).

31. Katz, R. Magma dynamics with the enthalpy method: Benchmark solutions and magmatic focusing at mid-ocean ridges. J. Petrol. 49 (2008).

32. Knepley, M., Katz, R. \& Smith, B. Developing a geodynamics simulator with PETSc. In Bruaset, A. \& Tveito, A. (eds.) Numerical Solution of Partial Differential Equations on Parallel Computers, vol. 51 of Lecture Notes in Computational Science and Engineering, 413-438 (Springer-Verlag, 2006).

33. Balay, S. et al. PETSc Web page (2001). Http://www.mcs.anl.gov/petsc.

34. Katz, R., Knepley, M., Smith, B., Spiegelman, M. \& Coon, E. Numerical simulation of geodynamic processes with the Portable Extensible Toolkit for Scientific Computation. Phys. Earth Planet. In. 163, 52-68 (2007).

35. Karato, S. \& Wu, P. Rheology of the upper mantle - a synthesis. Science 260, 771-778 (1993). 
36. Hirth, G. \& Kohlstedt, D. Rheology of the upper mantle and the mantle wedge: A view from the experimentalists. In Eiler, J. (ed.) Inside the Subduction Factory, vol. 138 of AGU Geophys. Monograph, 83-105 (Am. Geophys. Union, Washington DC, 2003).

37. Conder, J. A case for hot slab surface temperatures in numerical viscous flow models of subduction zones with an improved fault zone parameterization. Phys. Earth Planet. In. 149, 155-164 (2005).

38. Tichelaar, B. W. \& Ruff, L. Depth of seismic coupling along subduction zones. J. Geophys. Res. 98, 2107-2037 (1993).

Acknowledgements We are grateful to T. Grove and E. Lev for their free exchange of ideas and data concerning their paper ${ }^{6}$, and to C. Langmuir for comments that helped us to improve the manuscript. We thank Ellen Syracuse for providing hypocentral locations. Numerical models were run on computational clusters at the Oxford Supercomputing Centre.

Competing Interests The authors declare that they have no competing financial interests.

Contributions of Authors Katz wrote the code for the numerical experiments; England carried out the re-analysis of depth-to-slab (Figure 3 and Supplementary Material). The authors participated equally in developing the ideas presented in this paper, and in writing it.

Correspondence Correspondence and requests for materials should be addressed to Philip England (email: philip@ earth.ox.ac.uk).

\section{Methods}

\section{Calculations of Thermal Structure of Subduction Zones}

Our calculation of the thermal structure of subduction zones employs a finite-volume discretization of the incompressible, variable-viscosity Stokes equation and steady-state, advection-diffusion energy equation on a uniformly spaced, staggered cartesian mesh ${ }^{32}$. It uses a Newton-Krylov solver provided by the Portable, Extensible Toolkit for Scientific Computation ${ }^{33,34}$. The code has been benchmarked against other numerical solutions for the this type of problem ${ }^{10}$. The viscosity $\eta$ is given by an Arrhenius law for diffusion creep of olivine

$$
\eta=A \exp \left(\frac{E+P V^{*}}{R T}\right)
$$

with activation energy $E$ and activation volume $V^{*}$ of $375 \mathrm{~kJ} / \mathrm{mol}$ and $5 \times 10^{-6} \mathrm{~m}^{3} / \mathrm{mol}$, respectively, and pre-exponential $A=1.8 \times 10^{7} \mathrm{~Pa}^{35,36}$.

The domain is composed of three subdomains, the slab, the wedge, and the overlying lid. Velocity in the slab subdomain is prescribed using the convergence rate and the slab dip; velocity in the lid is forced to equal zero. Within the wedge we solve the incompressible Stokes equation with no buoyancy term. There are no-slip conditions on the wedge-lid and wedge-slab boundaries, and there is a no-stress condition applied at the wedge inflow/outflow boundary. Temperature is fixed at zero on the top of the domain; the 
slab is given a temperature profile using the 1D conducting slab solution; this solution is also applied to fix the temperatures on the inflow boundary. Complete details are provided in ref. ${ }^{10}$.

The domain is 600 by $600 \mathrm{~km}$, oriented as shown in Figure 1, with a mesh spacing of $1 \mathrm{~km}$. We have checked convergence of our solutions by comparing them, for combinations of parameters that span the range of interest, against solutions with mesh spacing of $0.5 \mathrm{~km}$. We find differences between the two meshes at the level of less than $10^{\circ} \mathrm{C}$ between temperatures calculated on the top of the slab or near the wedge corner.

An important parameter in thermal models of subduction zones is the depth at which the slab couples to the mantle wedge with a no-slip condition ${ }^{37}$. The maximum extent of shallowly dipping thrust faulting on the plate interface in subduction zones is about $45 \mathrm{~km}^{38}$ and, allowing for a transitional zone of aseismic sliding below this depth, we fix the depth to the top of full coupling between wedge and slab at $56 \mathrm{~km}$.

\section{Measurement of Depth to Top of Slab Beneath Arcs}

We apply the methods of ref. ${ }^{8}$ to the 45 arc segments studied by ref. ${ }^{13}$. For each arc segment we formed cross-sections of the seismicity and estimated $D$ as described by ref. ${ }^{8}$. We used the tables given in the supplementary information of ${ }^{13}$ to check whether the segment boundaries of the two studies agreed; except where noted in the table in the Supplementary Material, the disagreements were minor and we used the segment boundaries of ref. ${ }^{8}$.

We could not obtain reliable estimates of $D$ for seven arcs, either because of the sparsity of earthquakes or because the volcanoes are spread out so widely that a clear volcanic front cannot be identified (see remarks on individual arcs, in the Supplementary Material). We combined the remaining volcanoes into 35 arc segments for which $D$ estimated by the two different methods can be reconciled. An example of illustrating the two approaches, and their reconciliation in one of the more problematic arcs, can be seen in Figure S2. The Marianas, Lesser Antilles, and Vanuatu arcs are treated as single arcs here; each is split into northern and southern segments by ref. ${ }^{13}$. 


\section{A DEPTH TO THE TOP OF THE SLAB BENEATH VOLCANIC ARCS}

England et al. (2004) found a strong negative correlation between $D$ and the descent speed of the slab for 22 volcanic arcs for which they could identify well-defined locations for the slab. That correlation was questioned by Syracuse and Abers (2006), who included in their study a half-dozen arc segments with steep $\left(>65^{\circ}\right)$ dips, which England et al. had excluded. Here we revisit this issue, finding 35 arc segments for which $D$ estimated by the two different sets of authors can be reconciled, and amplifying the reasons given by England et al. (2004) for excluding arcs for which they could not obtain reliable estimates of $D$.

The purpose of this exercise is to derive a set of estimates of $D$ that may be used to test hypotheses about the relations between the thermal structure of arcs and the melting processes that take place beneath them. Several of the arcs that Syracuse and Abers (2006) identified as discordant from the trend identified by England et al. (2004) are shorter than $2-400 \mathrm{~km}$; for such segments, one should expect perturbations to the thermal regime, caused by flow around the edges of the slab (Kincaid and Griffiths 2003). In the case of the Philippine arcs, cold material from adjacent trenches may cool the wedge. For a few arcs, the distribution of seismicity makes determination of $D$ problematic.

The total length of the arcs investigated by England et al. (2004) and Syracuse and Abers (2006) is about $30,000 \mathrm{~km}$; there is approximately a further $6,000 \mathrm{~km}$ of arc below which the seismicity is absent, or too sparse for measurement of $D$ by the methods employed by either set of authors. In the notes accompanying the Table (below) we identify the seven arcs (total length $\sim 4000 \mathrm{~km}$ ) for which $D$ was measured by Syracuse and Abers (2006), but which we have not included in our analysis, for one or more of the reasons given in the previous paragraph.

\section{A NOTE ON BACK-ARC SPREADING}

As did England et al. (2004); England and Wilkins (2004), we use for the convergence rate $V$ the rate of motion between the bounding plates, and do not include the rate of any backarc spreading that occurs. Our rationale is based on the analysis that leads to the scaling relations developed in this paper. Temperatures in the mantle wedge are determined by the advection of heat by flow in the wedge. In subduction zones without back-arc spreading, all the flow is directed around the wedge corner, thus carrying heat beneath the arcs. When back-arc spreading occurs, there is greater net flow in the wedge, but the increased flow goes out through the back-arc spreading centre, rather than around the corner of the wedge (see Ribe 1989; Conder et al. 2002). Because the system is dominated by the advection of heat by the flow, it is reasonable to expect that any extra heat brought into the wedge by the back-arc spreading goes - with the additional flow - out through the back-arc, rather than contributing extra heat to the region below the arc. Therefore, the amount of heat advected towards the arc in a subduction zone with back-arc spreading should be comparable to the amount that would be carried in the absence of spreading. For this reason, we calculate $V$ excluding the rate of back-arc spreading. 


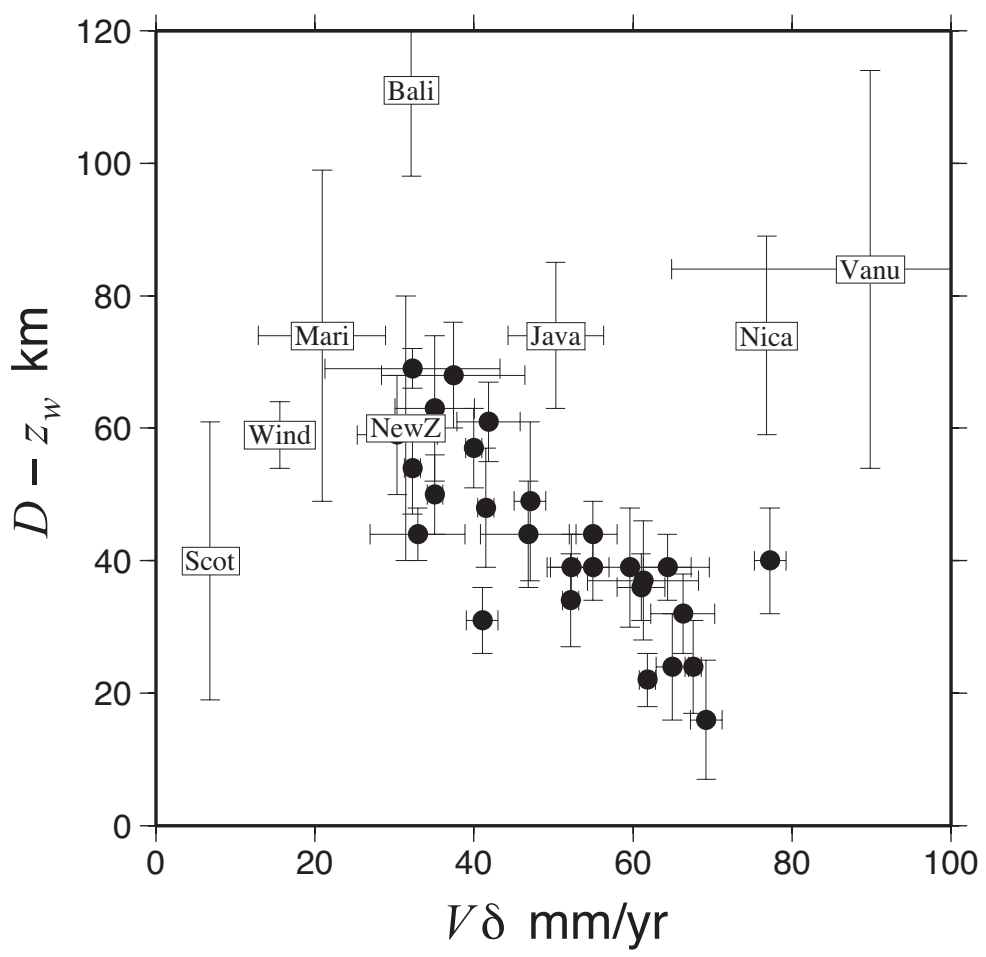

Figure S1. Figure corresponds to Figure 3a of the main text, except that arcs specifically discussed here are identified by their four-letter abbreviations (Table S1).

\section{Correlation between $D$ and $V \delta$}

In this paper we use the correlation between the depth to the top of the slab $D$, inferred from the distributions of intermediate-depth seismicity in the subduction zones and $V \delta$, the product of the convergence rate of the plates with the dip of the slab. We note in the body of the text that the rank-order correlation coefficient between $D$ and $V \delta$ is $R=-0.34$ which, for a sample set consisting of 35 observations, has a probability of $2.6 \%$ of arising by chance. Because the distributions of $D$ and $V \delta$ are apparently non-normal as shown in Figure S2, we first establish that this probability is robust. We generated $10^{6}$ random sampling sets of the data of Table S1, holding $V \delta$ for each arc at its observed value, but shuffling the values of $D$ and adding noise from a uniform distribution of width equal to the uncertainty in $D$ in Table S1. The distribution of $R$ for these samples is normal and, indeed, only $2.6 \%$ of these values are lower than $R=-0.34$ (Figure S2c).

The significance of this correlation is sensitive to the presence of a small number of arcs that have large uncertainties in the measurement of $D$. To quantify this sensitivity, we exclude from the data set the $5 \operatorname{arcs}$ for which the uncertainty in $D$ is $15 \mathrm{~km}$ or greater. These are: New Zealand and Mariana, which lie on the general trend, and Vanuatu, Nicaragua, and Scotia, which lie off the trend (Figure S1). The rank-order coefficient for the remaining 30 arcs is -0.59 which, for a sample set containing 30 observations, has a probability of $6 \times 10^{-4}$ of arising 
by chance. However, these are 30 observations chosen from among 35, with the criterion for exclusion being the magnitude of the uncertainty in $D$. It is reasonable to ask whether, by excluding these 5 arcs from the data set, we have artificially increased the significance of the correlation.

To address this question, we calculate the distribution of $R$ obtained by randomly shuffling the data of Table S1 and removing from each sample the 5 observations with the largest rank-order difference (i.e. those observations that detract most from the significance of the correlation). We then recalculate $R$ for each reduced sample of 30 arcs, and discard all samples with values of $R$ is greater than -0.34 ; the result is shown in Figure S2d. This procedure is designed to be more biased towards increasing the significance of $R$ than our criterion of exclusion of arcs on the grounds of uncertainty in $D$. It yields a population of samples with correlation coefficients $R$ that are at least as significant as that shown by the full data set. Only $2.3 \%$ of the samples have a value of $R$ that is more negative than -0.59 . This indicates that our exclusion of the arcs with high uncertainty in $D$ has a low probability of artificially increasing the significance of the correlation.

Six segments of arc - Scotia, Java, Bali, Nicaragua, West Indies and Vanuatu, total length about 4,000 km - exhibit values of $D$ that do not show the same correlation with descent speed seen for the other arcs. The analysis confirms the conclusion of Syracuse and Abers (2006) that some arcs - particularly those with slab dips above $60^{\circ}$ - do not fit the trend observed by England et al. (2004). The analysis also reaffirms, however, the conclusion of England et al. (2004) that there is a significant correlation between $D$ and the descent speed $(\sim V \delta)$ of the slab for the remaining 30 arcs, whose total length is about 22,000 km (Figure S1 and main text). 

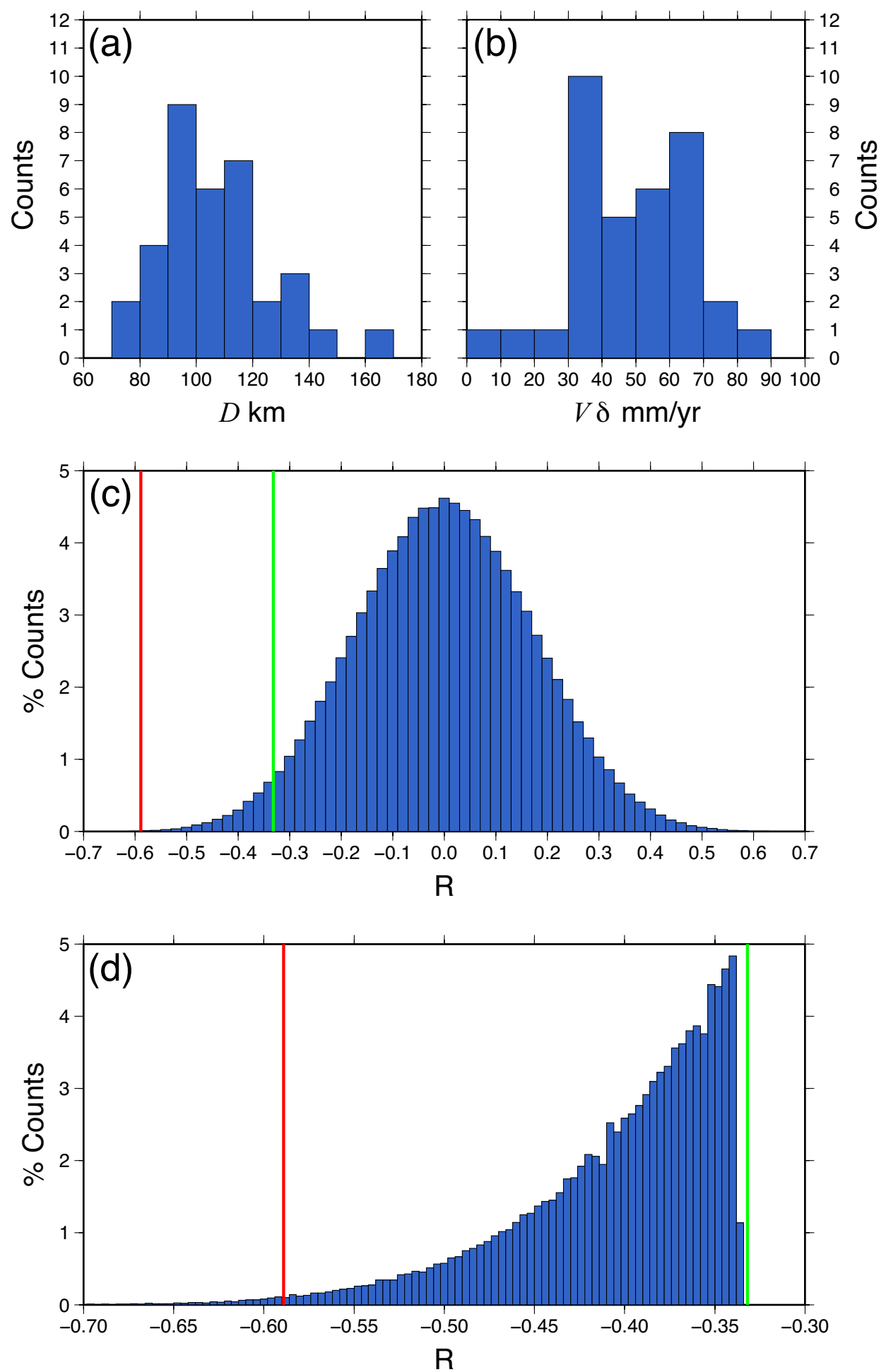

Figure S2. Panel (a) Distribution of measured values of depth to the top of the slab, $D$, beneath volcanic arcs (Table S1). Panel (b) Distribution of convergence rate $V$ multiplied by slab dip $\delta$ for these arcs. Panel (c) The distribution of rank-order coefficient $R$ obtained by $10^{6}$ random shufflings of the data of panels (a) and (b). The green line corresponds to $R=-0.34$ and the red line to $R=-0.59$ (see text). Panel (d) The distribution of rank-order coefficient $R$ obtained by $3 \times 10^{7}$ random shufflings of the data of panels (a) and (b), with the removal of 5 points from each set, as describe in the text. Only those realizations with $R<-0.34$ are retained. 
England and Katz: Locations of Volcanic Arcs, Supplementary Material 5

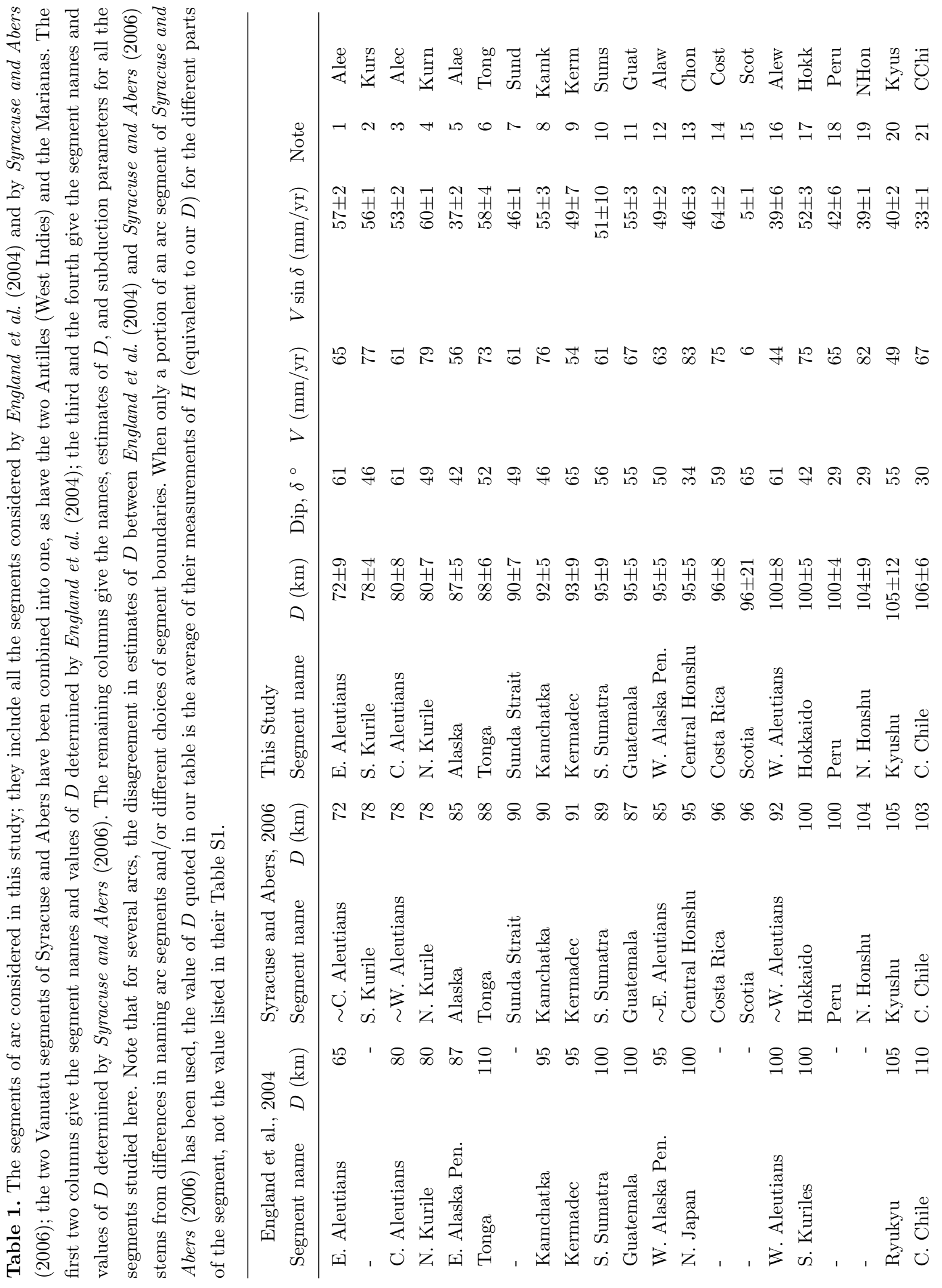




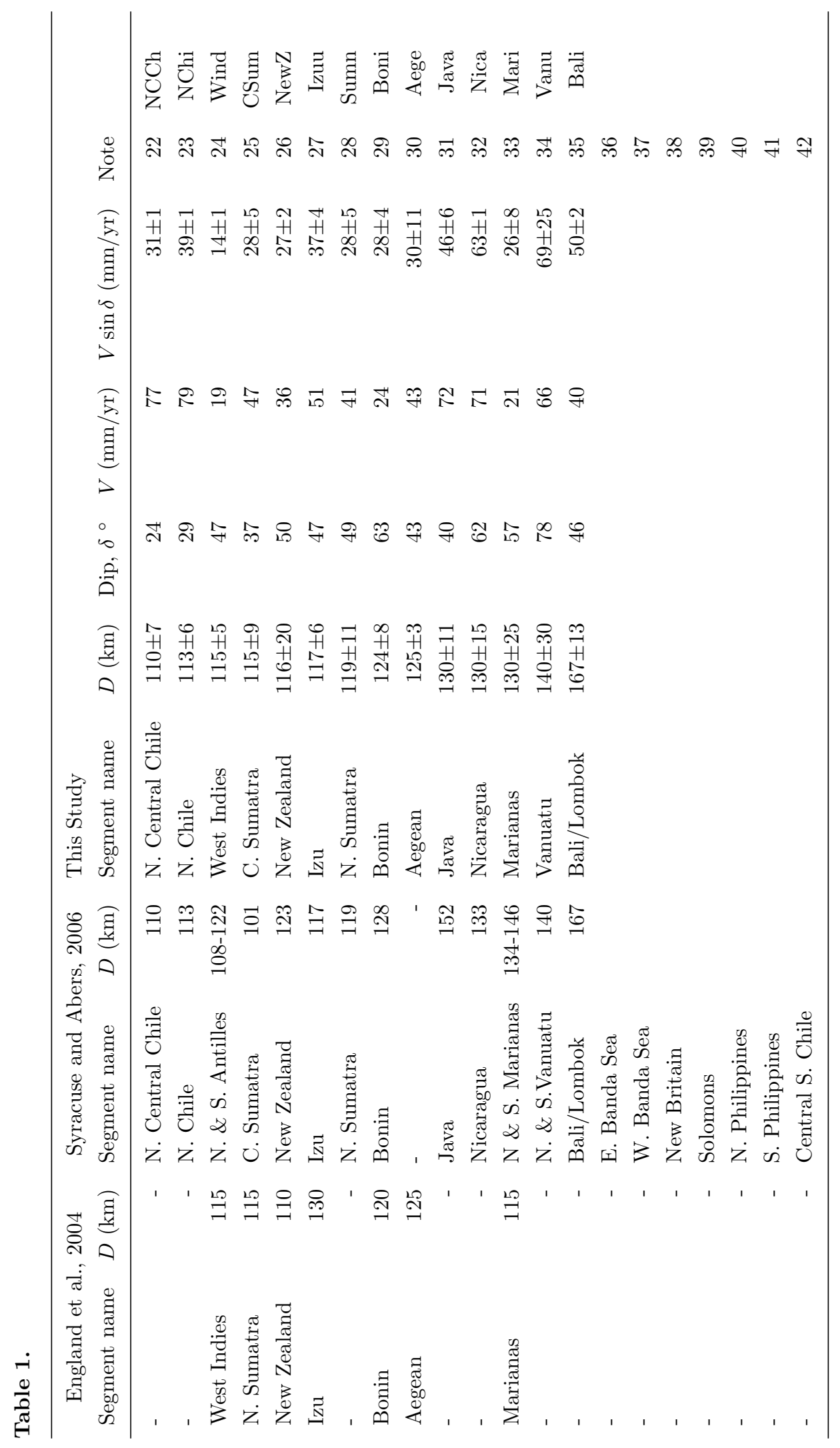




\section{Notes to Table}

The designation "From Syracuse and Abers (2006)" indicates that we have used the procedure of England et al. (2004) to a segment defined by Syracuse and Abers (2006) (otherwise, we use the segment boundaries defined by England et al. (2004)). There is one exception to this procedure: in the case of N. Honshu, there are no entries in Syracuse and Abers' supplementary information, so we accept their estimate of $D$ ( $\mathrm{H}$ in their notation). Uncertainties in $D$ are given as in the original studies or, for those segments (the majority) that were studied by each set of authors, as the larger of the two uncertainties. Estimates of descent speed are from the respective original papers, except for Kyushu and the Marianas, as noted. This study was made before the publication of the MORVEL plate velocity model (DeMets et al. 2010), but we have checked that the figures we present would not be significantly affected if the newer velocities were to be employed.

(1) E. Aleutians: Central Aleutians of Syracuse and Abers (2006). England et al. (2004), Figure 3.

(2) S. Kurile: From Syracuse and Abers (2006). Contains southern part of North Kuriles and northern part of South Kuriles segments of England et al. (2004). Estimate of D by England et al. (2004), Figure 5, agrees with that of Syracuse and Abers (2006).

(3) C. Aleutians: Eastern part of West Aleutians of Syracuse and Abers (2006), between $181^{\circ} \mathrm{E}$ and $186^{\circ} \mathrm{E}$. We use $D$ of $80 \mathrm{~km}$, picked from the cross-section of seismicity (England et al. (2004), Figure 4).

(4) N. Kurile: Estimate of $D$ by England et al. (2004), Figure 5, agrees with that of Syracuse and Abers (2006).

(5) Alaska: Corresponds approximately to E. Alaskan Peninsula of England et al. (2004), Figure 6 . We use the $D$ from that study, but correct the dip, which was misprinted by England et al. (2004).

(6) Tonga: England et al. (2004), Figure 17, considered a shorter section of the Tonga arc than did Syracuse and Abers (2006). We have applied the procedure of England et al. (2004) to the longer segment of arc, and obtain the same value of $D$ as do Syracuse and Abers (2006).

(7) Sunda Strait: From Syracuse and Abers (2006).

(8) Kamchatka: Estimate of $D$ by England et al. (2004), Figure 8, agrees with that of Syracuse and Abers (2006).

(9) Kermadec: Estimate of $D$ by England et al. (2004), Figure 9, differs by $4 \mathrm{~km}$ from that of Syracuse and Abers (2006); we use the average of the two estimate of D.

(10) S. Sumatra: We use $D$ of $100 \mathrm{~km}$, picked from the cross-section of seismicity (England et al. (2004), Figure 13).

(11) Guatemala: Corresponds only to the Guatemala portion of the Guatemala-El Salvador segment of England et al. (2004), Figure 10. Estimate of $D$ by England et al. (2004) agrees with estimates of Syracuse and Abers (2006), for the volcanoes of this section. The El Salvador 
section is included with the Nicaragua section (below) because it appears to form part of the same, concave-towards-trench arc segment.

(12) W. Alaska Peninsula: East Aleutians of Syracuse and Abers (2006). We use D of 95 $\mathrm{km}$, picked from the cross-section of seismicity (England et al. (2004), Figure 7). Average for $D$ given by Syracuse and Abers (2006) over the same range of longitude is $90 \mathrm{~km}$.

(13) Central Honshu: The Central and Northern Honshu arc segments of Syracuse and Abers (2006) correspond the N. Japan segment of England et al. (2004), Figure 11. We use the estimate of $D$ by England et al. (2004).

(14) Costa Rica: From Syracuse and Abers (2006); Syracuse et al. (2008).

(15) Scotia: From Syracuse and Abers (2006). Note that this arc is short (about 400km), the slab dips steeply, and there is rapid back-arc spreading, so 3D effects (Kincaid and Griffiths 2003) may be important.

(16) W. Aleutians: Western part of West Aleutians of Syracuse and Abers (2006), between $176^{\circ} \mathrm{E}$ and $180^{\circ} \mathrm{E}$. Shallower values of $D$, reported by Syracuse and Abers (2006) may reflect extrapolation of the location of top of slab based on seismicity further to the east. We use $D$ of $100 \mathrm{~km}$, picked from the cross-section of seismicity (England et al. (2004), Figure 4).

(17) Hokkaido: Corresponds to S. Kuriles segment of England et al. (2004), Figure 12. Estimate of $D$ by England et al. (2004), agrees with that of Syracuse and Abers (2006).

(18) Peru: From Syracuse and Abers (2006).

(19) N. Honshu: From Syracuse and Abers (2006).

(20) Kyushu: Corresponds to Ryukyu segment of England et al. (2004), Figure 16. Estimate of $D$ by England et al. (2004), agrees with that of Syracuse and Abers (2006). Syracuse and Abers (2006) use Philippine-South China angular velocity of Sella et al. (2002), which yields a descent speed of $58 \pm 1 \mathrm{~mm} / \mathrm{yr}$; we use, as do England et al. (2004) the Philippine-Eurasia angular velocity of Seno et al. (1993).

(21) Central Chile: The estimate of England et al. (2004), Figure 18, differs by $7 \mathrm{~km}$ from that of Syracuse and Abers (2006). We take the average of the two values of $D$.

(22) N. Central Chile: From Syracuse and Abers (2006).

(23) N. Chile: From Syracuse and Abers (2006).

(24) West Indies: We use $D$ of $115 \mathrm{~km}$, picked from the cross-section of seismicity (England et al. (2004), Figures 23 \& 24). We combine the two segments.

(25) C. Sumatra: Seismicity defines a clear top to the slab at $115 \mathrm{~km}$ beneath the volcanoes (England et al. (2004), Figure 22); depth given by Syracuse and Abers (2006) appears to be constrained by a small number of earthquakes at much shallower depth.

(26) New Zealand: The estimate of England et al. (2004), Figure 19, differs by $13 \mathrm{~km}$ from that of Syracuse and Abers (2006). We take the average of the two values of $D$.

(27) Izu: Re-examination of the cross-section of England et al. (2004), Figure 27, in the light of the analysis of Syracuse and Abers (2006) leads us to accept their estimate of $D$.

(28) N. Sumatra: From Syracuse and Abers (2006).

(29) Bonin: The estimate of England et al. (2004), Figure 25, differs by $8 \mathrm{~km}$ from that 
of Syracuse and Abers (2006). We take the average of the two values of D. Dip, convergence rate, and descent speed taken from Syracuse and Abers (2006).

(30) Aegean: England et al. (2004), Figure 26.

(31) Java: The segment used by Syracuse and Abers (2006) is longer than that of England et al. (2004). We have applied the procedure of England et al. (2004) to the longer segment of arc, and obtain a value for $D$ of 130 beneath the frontal volcanoes. This arc is much wider than most of the others considered here, and the value of $150 \mathrm{~km}$ for $D$ given by Syracuse and Abers (2006), reflects an average for all volcanoes in the arc; their estimates of $D$ for the volcanoes closest to the volcanic front lie in the range 130 to $140 \mathrm{~km}$.

(32) Nicaragua: From Nicaragua and El Salvador of Syracuse and Abers (2006), who quote an uncertainty for $D$ of $4 \mathrm{~km}$ for this segment. We base our value of $15 \mathrm{~km}$ for the uncertainty on the range in the depth to the top of the intermediate-depth seismicity in the 10-km band either side of the volcanic front, where the local dip of the top of the slab appears to be greater than $70^{\circ}$; this range also appears to be consistent with the range of $D$ given in the supplementary data of Syracuse and Abers (2006).

(33) Marianas: combines N. and S. Marianas of Syracuse and Abers (2006). Method of England et al. (2004) (cross-section shown in their Figure 20, and in Figure S3 here) indicates a minimum value for $D$ of $115 \mathrm{~km}$. Except in the southern-most Marianas, where relatively fewer earthquakes define the location of the slab beneath the arc, the method of Syracuse and Abers (2006) indicates that the volcanoes lie between the 100-km and 150-km contours of depth-to-slab (Figure S3). We assign $D=130 \pm 25 \mathrm{~km}$, which covers both estimates. Syracuse and Abers (2006) use Pacific-Philippine angular velocity of Sella et al. (2002), which yields a descent speed of $17 \pm 1 \mathrm{~mm} / \mathrm{yr}$; we use, as do England et al. (2004) the Pacific-Philippine angular velocity of Seno et al. (1993).

(34) Vanuatu: Syracuse and Abers (2006). Slab essentially vertical beneath arc. $D$ could be anywhere between $110 \mathrm{~km}$ and $170 \mathrm{~km} ; \mathrm{N}$ and S. Vanuatu combined as single segment.

(35) Bali/Lombok: From Syracuse and Abers (2006).

(36) E. Banda Sea: Syracuse and Abers (2006). We do not include this segment, because it contains about $250 \mathrm{~km}$ along-strike length of slab that is highly curved (radius of curvature about $200 \mathrm{~km}$ ) giving a likelihood of 3D effects (Kincaid and Griffiths 2003); in addition, both $D$ and the descent speed are poorly constrained.

(37) W. Banda Sea: From Syracuse and Abers (2006). Reliable intermediate-depth seismicity only $\mathrm{E}$ of $122^{\circ} \mathrm{E}$, where we find $D=115 \mathrm{~km}$. However, this section of arc is only $150 \mathrm{~km}$ long, and we do not include it because of the likelihood of 3D effects (Kincaid and Griffiths 2003).

(38) New Britain: Syracuse and Abers (2006). Short arc segment, small radius of curvature; using techniques of England et al. (2004) $D$ is uncertain. $V$ uncertain because relative motions of bounding plates are not well constrained (DeMets et al. 2010). Not used in this study, although values for $D$ and $V \delta$ (Syracuse and Abers 2006) are consistent with the correlation described in this paper.

(39) Solomons: Syracuse and Abers (2006). Not used here; too few hypocenters beneath arc 
for cross-section to be interpretable. Slab changes dip rapidly in region immediately beneath the arc; top of slab could be as shallow as $90 \mathrm{~km}$, or as deep as $150 \mathrm{~km}$. Apart from one volcano, $200 \mathrm{~km}$ to the north, and near a corner in the slab, the volcanoes define an arc less than $200 \mathrm{~km}$ long. In addition, $V$ uncertain because relative motions of bounding plates are not well constrained (DeMets et al. 2010).

(40) N. Philippines: Syracuse and Abers (2006). Arc too diffuse to obtain estimate of $D$ using techniques of England et al. (2004). Different, reasonable, assumptions about which volcanoes define the arc front lead to small circles with $D$ between 100 and $150 \mathrm{~km}$. This result is also borne out by the depth-to-slab contours of Syracuse and Abers (2006). Additionally, convergence along the East Luzon Trough, less than $200 \mathrm{~km}$ to the east of the arc, presumably delivers cold material to the wedge, and produces a distinctive thermal structure that could not be analyzed with any simple model for subduction zones.

(41) S. Philippines: Syracuse and Abers (2006). A range of small circles defining the arc front can be found, depending upon the choice of volcanoes; the intermediate-depth seismicity dips steeply beneath these lines, and estimates of $D$ lie between about $100 \mathrm{~km}$ and $180 \mathrm{~km}$. As with the Northern Philippines, there may be delivery of cold material to the wedge by subduction of opposite vergence within 200-300 km of the arc.

(42) Central S. Chile: Segment of Syracuse and Abers (2006); we do not use this segment, because the very small number of earthquakes beneath these volcanoes makes it impossible to define accurately the location of the slab. Cross-section drawn using the procedure of England et al. (2004), suggests that the top of the slab may be as much as $20 \mathrm{~km}$ deeper than the $80 \mathrm{~km}$ Syracuse and Abers (2006), obtained by fitting a plane through the seismicity. 

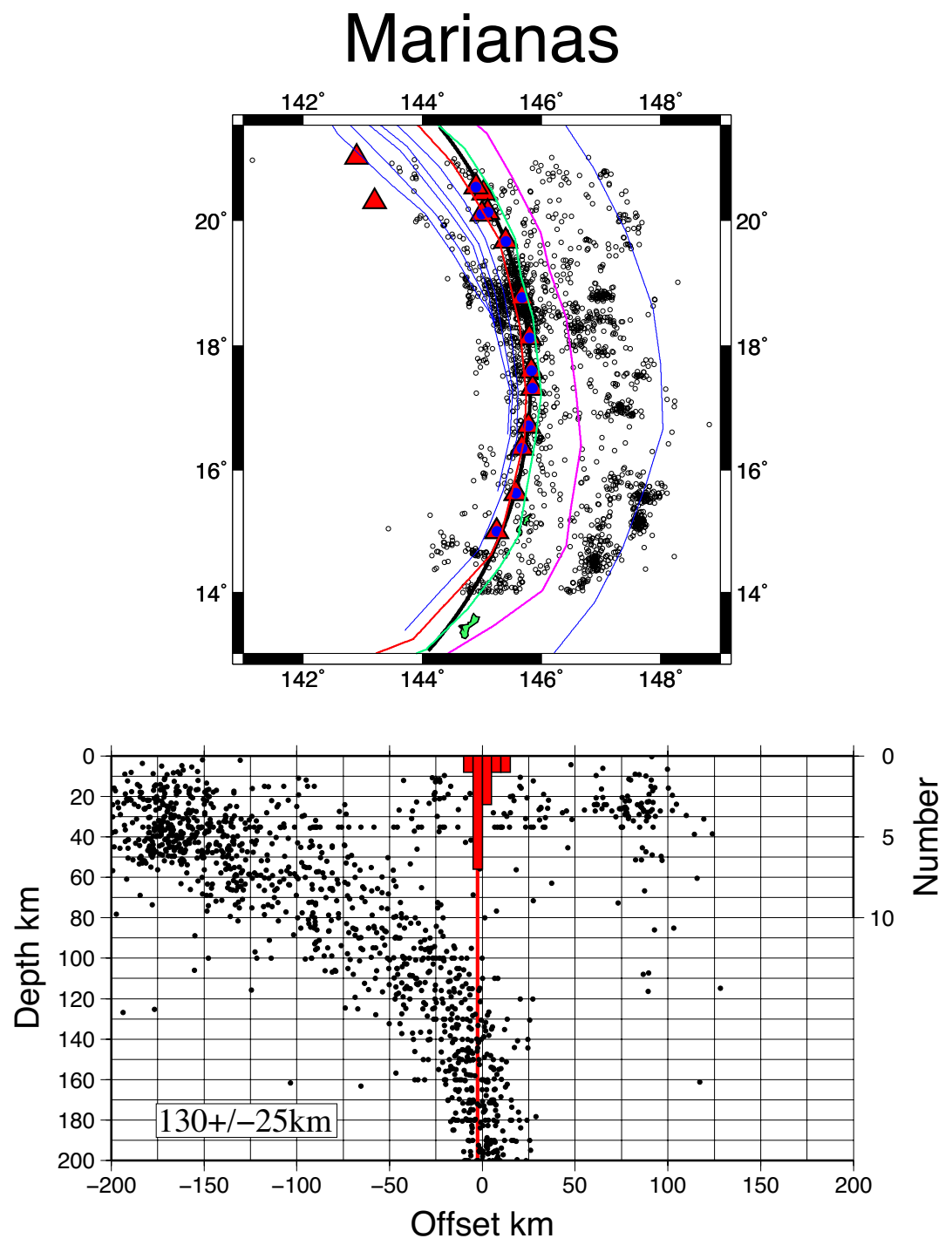

Figure S3. Map and composite cross-section of the distribution of earthquakes and volcanoes in the Mariana arc, following the methods described by England et al. (2004). In the upper panel, epicentres of earthquakes from the catalogue of Engdahl et al. (1998) are shown by open circles, and the locations of volcanoes from Siebert and Simkin (2002) are shown by triangles. The black line shows the bestfitting small circle through the locations of the volcanoes of the volcanic front, which are denoted by blue dots within their triangles. Coloured lines show contours of the depths to the top of the slab determined by Syracuse and Abers (2006). The easternmost contour corresponds to a depth of $6 \mathrm{~km}$; purple, green and red correspond, respectively, to 50, 100, and $150 \mathrm{~km}$. Deeper contours, at intervals of $50 \mathrm{~km}$, are shown in blue. In the lower panel, the hypocentres of the earthquakes shown in the upper panel are plotted with the horizontal coordinate being the offset from the small circle. Histogram on the top of this panel (scale to right) indicates the numbers of volcanoes located within 5-km bins of distance from the small circle. Vertical line indicates chosen location of the volcanic front. 


\section{B THERMAL CALCULATIONS}

\section{B.1 Scaling}

Figure 2 of the main text shows that the temperatures in our variable-viscosity simulations obey the same scaling relations that were derived for the isoviscous case. The preservation of the scaling from the isoviscous case considered by England and Wilkins (2004) is not unexpected. On dimensional grounds, the temperature can depend only upon $V, r$ and the thermal diffusivity $\kappa$ (in the combination $V r / \kappa$ ), and upon dimensionless parameters. The only dimensionless parameter in the constant-viscosity problem is the dip $\delta$ of the slab; the temperature-dependent problem has an additional dimensionless parameter representing the temperature-sensitivity of the rheology, but this parameter is constant for all calculations, so it will not enter into the scaling. Thus, for either problem, temperature should scale with $V r / \kappa$ and some power of the dip.

The scaling can be understood from the balance between advection and diffusion of heat near the wedge corner (England and Wilkins 2004). The scale for the advection of heat is set by the volume flux of mantle toward the wedge corner, which is proportional to $\operatorname{Vr} \delta$, so we expect the maximum temperature in the wedge to increase with $V r \delta$. But heat is also conducted out of the wedge corner, principally down the steep thermal gradient in the boundary layer on top of the slab. The thickness of this thermal boundary increases, for fixed $V \delta$, approximately in proportion to $\delta$ (England and Wilkins 2004), the second power of $\delta$ in the scaling therefore arises because for fixed $V r \delta$, less heat is conducted out of the wedge corner at large dip than at small dip.

\section{B.2 Uncertainties in temperatures}

In formalizing this model of the thermal structure of subduction zones we have made several simplifications and we do not expect that our calculations will precisely represent the temperature fields in real subduction zones. We have treated the dip of the slab as constant, at the value representative of the depth range between the base of the plate and $200 \mathrm{~km}$, whereas in reality the dip shallows to $10^{\circ}-20^{\circ}$ in the upper parts of the plate boundary. As England and Wilkins (2004) and Conder (2005) show, reasonable assumptions about the dissipation of heat on the plate boundary (the subduction fault between the trench and the wedge corner) can lead to temperatures at the top of the slab that are $\sim 100-200^{\circ} \mathrm{C}$ higher than we calculate here. The details of the thermal structure of the plate boundary have, however, only a minor influence on temperatures in the wedge interior because advection in the wedge is the dominant control on the temperatures there (England and Wilkins 2004). We carried out experiments in which the coupling depth was 44 or $68 \mathrm{~km}$, and found that these changes, respectively, raised and lowered peak temperatures in the wedge beneath the arcs by about

$50^{\circ} \mathrm{C}$. We also allowed the parameters $E$ and $A$ in the rheology (see Methods) to change from the values used here; changing $E$ by $\pm 10 \%$ changed temperatures in the interior of the wedge 
by about $\pm 50^{\circ} \mathrm{C}$, and decrease (increase) in $A$ by a factor of 2.5 caused increase (decrease) in wedge temperatures by $\sim 50^{\circ} \mathrm{C}$.

Each of these sets of experiments yields the same form of scaling of temperature with the subduction parameters that we describe above. We believe, therefore, that our model captures the correlations between subduction parameters and thermal structure.

\section{B.3 Thermal Erosion by Melt}

Here we estimate the potential for thermal erosion of the overlying lithosphere by nominally anhydrous magma rising out of the core of the wedge. We consider a $2 \mathrm{D}$ column of rock of width $w$ and height $h$ extending from the top of the nose of the mantle isotherm at temperature $T_{C}$ upward to the surface of the Earth. Within the column is a mixture of fluid magma and solid mantle in local volume proportion $\phi$. Each of these two phases has a distinct internal energy per unit mass $e_{i}$ and velocity $\mathbf{v}_{i}$, where $i$ can be either $f$ for the magma or $m$ for the matrix. We assume that they both have a density $\rho$, a thermal conductivity $k$, and a local temperature $T$. We will be concerned with the changing energy balance within this column as magma enters it from below. An integral representation of this balance is

$$
\frac{\mathrm{d}}{\mathrm{d} t} \int_{V} E \mathrm{~d} V=-\int_{\partial V}(\overline{\rho e \mathbf{v}}-k \boldsymbol{\nabla} T) \cdot \mathbf{n} \mathrm{d} S,
$$

where $E$ is the bulk internal energy per unit volume and overbars represent phase averages (i.e. $\left.\bar{q}=\phi q_{f}+(1-\phi) q_{m}\right)$. This equation states that changes in internal energy of the column are due to advection and diffusion of internal energy across its boundary. We have neglected contributions from kinetic and potential energy.

The mantle matrix has internal energy $e_{m}=c_{P}\left(T-T_{0}\right)$ while the magma has $e_{f}=$ $c_{P}\left(T-T_{0}\right)+L$, where $c_{P}$ is the specific heat at constant pressure and $L$ is the latent heat per unit mass. The bulk volumetric internal energy is thus

$$
E=\rho c_{P}\left(T-T_{0}\right)+\rho \phi L
$$

We assume that heat and mass can enter and leave the column only through the bottom and top, and that there is no flux through the sides. Then the temperature in the column depends only on height, going from $T_{C}$ at the bottom to $T_{S}$ at the surface. We approximate this as a two-part linear profile,

$$
T(z)= \begin{cases}T_{C} & 0 \leq z \leq z_{M}, \\ T_{C}+\left(T_{C}-T_{S}\right) \frac{z-z_{M}}{h-z_{M}} & z_{M}<z \leq h .\end{cases}
$$

Without thermal erosion due to upwelling magma, $z_{M}=0$ and energy diffuses out of the column at the surface at a rate $k\left(T_{C}-T_{S}\right) / h$, which is exactly balanced by the heat flux into the base of the column from the hotter mantle below, such that the temperature profile is in steady state. The effect of magmatic thermal erosion will be to push $z_{M}$ upward into the column. 
We consider magma entering the column from below. Because the phase densities are equal and the column has a fixed volume, the upward flux of magma into the column must be balanced by a downward flux of solid mantle out of the column. These occur at the same temperature, so the net advective heat transport into the column is $M L$, where $M$ is the rate of flow of magma into the column (mass per unit length per unit time). Finally, assuming that the influx of magma into the column is balanced by freezing within the column, we can take the average porosity within the column to be constant.

Applying all of these assumptions to equation (1), we can rewrite it as

$$
\frac{1}{2} w \rho c_{P} \Delta T \frac{\mathrm{d} z_{M}}{\mathrm{~d} t}=M L-\frac{k w \Delta T}{h-z_{M}}+\frac{k w \Delta T}{h},
$$

where $\Delta T=T_{C}-T_{S}$. This equation states that the rate of thermal erosion within the column is controlled by the flux of magma into the base of the column, the diffusion of heat out through the upper surface, and the supply of heat from the mantle below. The last term in (4) ensures that $z_{M}=0$ is a solution when $M=0$. Scaling $z$ with $h$ and $t$ with the characteristic thermal diffusion time $h^{2} \rho c_{P} / k$ gives the non-dimensional equation

$$
\dot{z}_{M}=2\left(\mathcal{M}-\frac{z_{M}}{1-z_{M}}\right),
$$

where $\mathcal{M}=M L h /(k w \Delta T)$, a dot above $z_{M}$ indicates the time derivative, and $z_{M}$ and $t$ are now dimensionless variables. In steady state, $z_{M}=\mathcal{M} /(\mathcal{M}+1)$; this relationship is plotted in Figure $\mathrm{S} 4$.

We may make reasonably well constrained estimates of the quantities contained in $\mathcal{M}$. According to our analysis, $H$ lies in the range $60-100 \mathrm{~km}$ (Figure $3 \mathrm{~b}$ ). We estimate the width of the column, $w$, from the width of the volcanic fronts, which is 10-15 km (England et al. 2004), so use $h / w \sim 5$. We take $\Delta T=1200 \mathrm{~K}, k=4 \mathrm{~W} \mathrm{~m}^{-1} \mathrm{~K}^{-1}$ and $L=4 \times 10^{5} \mathrm{~J} \mathrm{~kg}^{-1}$.

We first estimate the likely magnitude of $M$ for nominally anhydrous melting alone; calculation of dry melt production based on thermal models for subduction zones (Conder et al. 2002) yields an estimate of $\sim 2 \times 10^{-3} \mathrm{~kg} \mathrm{~m}^{-1} \mathrm{sec}^{-1}$ for the total rate of dry melt production in the wedge, which we may equate to $M$ if we assume that all of this melt passes through the column. Using this estimate gives $\mathcal{M} \sim 0.8$, so this degree of dry melt production can thermally erode the overlying temperature structure so that the $1200^{\circ} \mathrm{C}$ isotherm is advected upward by over $40 \%$ of its original depth. Melting at $1 / 4$ of this rate would raise the $1200^{\circ} \mathrm{C}$ isotherm by $20 \%$, or about $10 \mathrm{~km}$. Note that these estimates ignore the influence of along-arc focusing of the melt toward individual volcanic centres (e.g. d'Ars et al. 1995).

Estimates of the total melt production rate at arcs vary considerably, but are generally higher than the above estimate by more than a factor of two (e.g. Crisp 1984; Reymer and Schubert 1984; Dimalanta et al. 2002; White et al. 2006), so advection of heat by hydrous melt alone would be capable of raising the $1200^{\circ} \mathrm{C}$ isotherm by over $60 \%$ of its original depth. An equivalent effect would occur if less than half the heat advected by the hydrous melt were added to that carried by the dry melt. 


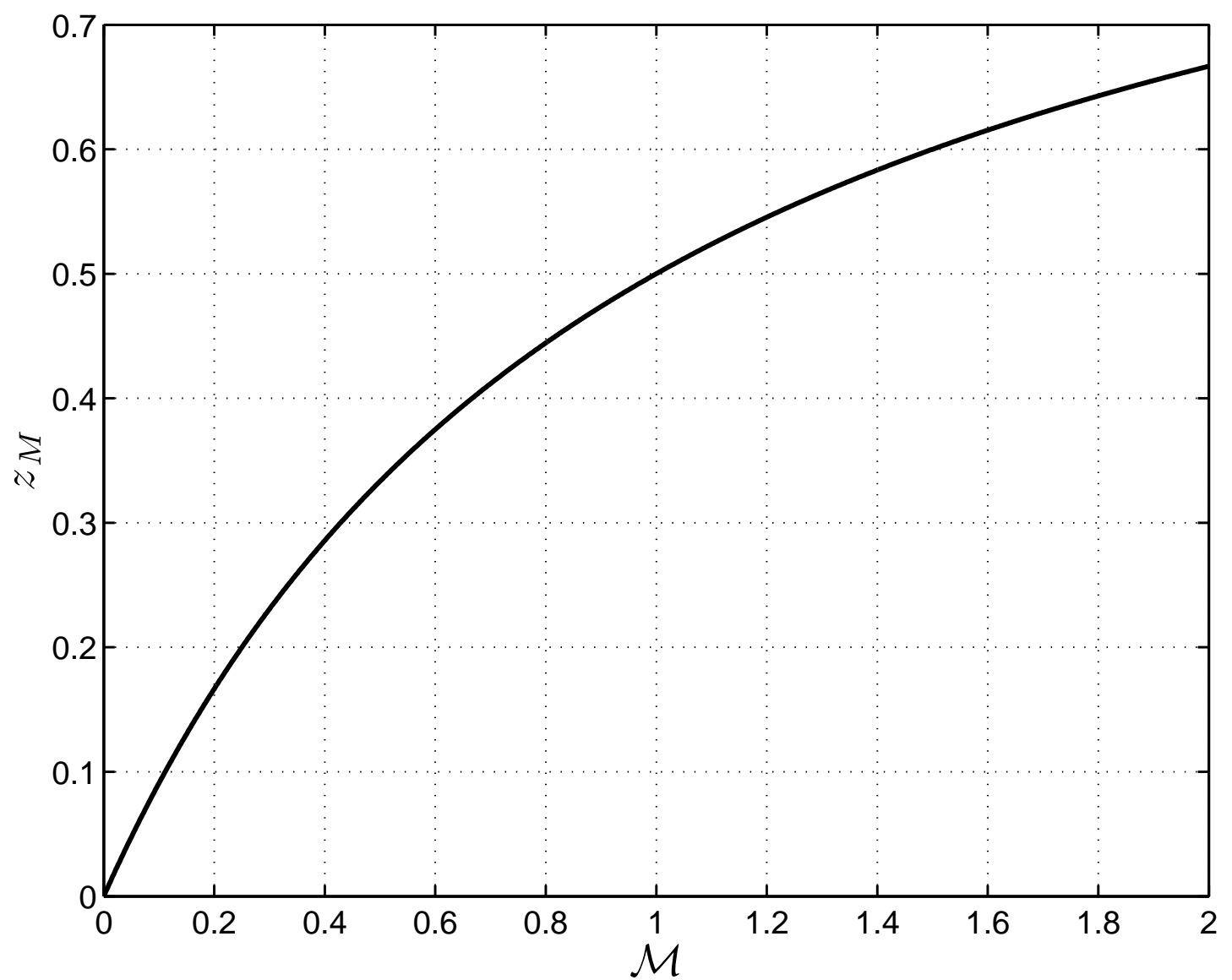

Figure S4. A plot of the steady-state, dimensionless height of thermal erosion distance as a function of the dimensionless control parameter, $\mathcal{M}$. The curve is given by $z_{M}=\mathcal{M} /(\mathcal{M}+1)$. 


\section{REFERENCES}

Conder, J., A case for hot slab surface temperatures in numerical viscous flow models of subduction zones with an improved fault zone parameterization, Phys. Earth Planet. In., 149(1-2), 155-164, doi:10.1016/j.pepi.2004.08.018, 2005.

Conder, J., D. Wiens, and J. Morris, On the decompression melting structure at volcanic arcs and back-arc spreading centers, Geophys. Res. Letts., 29(15), 1727, doi:10.1029/2002GL015390, 2002.

Crisp, J., Rates of magma emplacement and volcanic output, J. Volcanology and Geothermal Research, 20(3-4), 177-211, 1984.

d'Ars, J. B., C. Jaupart, and R. Sparks, Distribution of volcanoes in active margins, J. Geophys. Res., 100(B10), 20,421-20,432, 1995.

DeMets, C., R. G. Gordon, and D. F. Argus, Geologically current plate motions, Geophys. J. Int., 181, 1-80, doi:10.1111/j.1365-246X.2009.04491.x, 2010.

Dimalanta, C., A. Taira, G. Yumul, H. Tokuyama, and K. Mochizuki, New rates of western Pacific island arc magmatism from seismic and gravity data, Earth Planet. Sci. Lett., 202(1), 105-115, 2002 .

Engdahl, E., R. van der Hilst, and R. Buland, Global teleseismic earthquake relocation with improved travel times and procedures for depth determination, Bull. Seismol. Soc. Am., 88, 722-743, 1998.

England, P., and C. Wilkins, A simple analytical approximation to the temperature structure in subduction zones, Geophys. J. Int., 159(3), 1138-1154, doi:10.1111/j.1365-246X.2004.02419.x, 2004.

England, P. C., E. R. Engdahl, and W. Thatcher, Systematic variation in the depths of slabs beneath arc volcanoes, Geophys. J. Int., 156, 377-408, doi:10.1111/j.1365-246X.2003.02132.x, 2004.

Kincaid, C., and R. Griffiths, Laboratory models of the thermal evolution of the mantle during rollback subduction, Nature, 425(6953), 58-62, 2003.

Reymer, A., and G. Schubert, Phanerozoic addition rates to the continental crust and crustal growth, Tectonics, 3(1), 63-77, 1984.

Ribe, N., Mantle flow induced by back arc spreading, Geophys. J. Int., 1989.

Sella, G. F., T. H. Dixon, and A. Mao, REVEL: A model for Recent plate velocities from space geodesy, J. Geophys. Res., 10\%, 2002.

Seno, T., S. Stein, and A. Gripp, A model for the motion of the Philippine plate consistent with NUVEL1 and geological data, J. Geophys. Res., 98, 17,941-17,948, 1993.

Siebert, L., and T. Simkin, Volcanoes of the world: an illustrated catalog of Holocene volcanoes and their eruptions., Smithsonian Institution Digital Information Series GVP-3. http://www.volcano.si.edu/gvp/world, 2002.

Syracuse, E. M., and G. A. Abers, Global compilation of variations in slab depth beneath arc volcanoes and implications, Geochem. Geophys. Geosys., 7(5), 18, 2006.

Syracuse, E. M., G. A. Abers, K. Fischer, L. Mackenzie, C. Rychert, M. Protti, V. González, and W. Strauch, Seismic tomography and earthquake locations in the Nicaraguan and Costa Rican upper mantle, Geochem. Geophys. Geosys., 9(7), 1-22, doi:10.1029/2008GC001963, 2008.

White, S., J. Crisp, and F. Spera, Long-term volumetric eruption rates and magma budgets, Geochem. Geophys. Geosys., 7, Q03,010, doi:10.1029/2005GC001002, 2006. 